\title{
Carbonic anhydrase IV inhibits cell proliferation in gastric cancer by regulating the cell cycle
}

\author{
BUJIANG WANG $^{1 *}$, HAIZHONG JIANG ${ }^{1 *}$, XIANGXIANG WAN ${ }^{2}$, YAQING WANG ${ }^{3}$, \\ XIAOCAO ZHENG ${ }^{4}$, PEIFEI LI ${ }^{1}$, JUNMING GUO ${ }^{5}$, XIAOYUN DING ${ }^{1}$ and HAOJUN SONG ${ }^{1}$
}

\author{
${ }^{1}$ Department of Gastroenterology, Laboratory of Digestive Diseases, Ningbo First Hospital, Ningbo, Zhejiang 315010; \\ ${ }^{2}$ Department of Gastroenterology, The Third Hospital of Nanchang, Nanchang, Jiangxi 330002; ${ }^{3}$ Laboratory of Molecular \\ Medicine, Ningbo First Hospital; ${ }^{4}$ Department of Histopathology, Ningbo Diagnostic Pathology Center, Ningbo, \\ Zhejiang 315010; ${ }^{5}$ Department of Biochemistry and Molecular Biology, Zhejiang Provincial Key Laboratory \\ of Pathophysiology, Ningbo University School of Medicine, Ningbo, Zhejiang 315211, P.R. China
}

Received August 30, 2019; Accepted April 15, 2020

DOI: $10.3892 / \mathrm{ol} .2020 .11865$

\begin{abstract}
Carbonic anhydrase IV (CA4) is silenced in colorectal cancer. However, the effect of CA4 on the development of gastric cancer (GC) is poorly understood. The present study aimed to determine the role of CA4 in GC tumorigenesis and its underlying molecular mechanism. The levels of CA4 in GC cells and tissues were evaluated by reverse transcription-quantitative PCR and immunohistochemistry. CA4 expression was suppressed in GC cells and tissues compared with adjacent healthy tissues and normal human gastric epithelial cells, respectively. This reduced expression was significantly associated with tumor size, invasion and differentiation. Analyses with a real-time cell analyzer and clonogenic assays were conducted to validate the impact of CA4 on GC cell lines (AGS and HGC-27) and normal human gastric epithelial cell line (GES-1) proliferation. The effects of CA4 on the cell cycle in GC cells were determined by flow cytometry. The levels of CA4 and cell cycle-associated proteins were confirmed by western blotting. CA4 overexpression inhibited GC cell proliferation and reduced colony-forming ability, arrested the cell cycle in the G2/M phase, inhibited cyclin B1 and cyclin-dependent kinase 2 expression and induced p21 expression. These results indicate that CA4 may serve an important role in GC tumorigenesis by inhibiting cellular proliferation via regulating the expression of cell
\end{abstract}

Correspondence to: Dr Haojun Song or Dr Xiaoyun Ding, Department of Gastroenterology, Laboratory of Digestive Diseases, Ningbo First Hospital, 59 Liuting Street, Ningbo, Zhejiang 315010, P.R. China

E-mail: 061050225@163.com

E-mail: dyyyding@126.com

*Contributed equally

Key words: carbonic anhydrase, gastric cancer, proliferation, polymerase chain reaction, cell cycle cycle-associated proteins. CA4 may serve as a diagnostic biomarker and a potential therapeutic target in GC.

\section{Introduction}

Gastric cancer (GC) is caused by a combination of genetic and epigenetic alterations in gastric mucosal cells, such as TP53, PTEN gene mutations or DNA methylation or noncoding RNA regulation (1). GC is the fourth most common cancer worldwide (2); 951,600 new GC cases were reported, and 723,100 deaths occurred in 2012 (2). In general, the highest incidence rates of GC are observed in East Asian countries (3). As most cases are diagnosed at an advanced stage, the long-term survival rate is low (10-20\%) (4). However, when GC is diagnosed at an early stage, the long-term survival rate is high $(>90 \%)(5,6)$. The underlying mechanisms of GC tumorigenesis and recurrence are complex. Zinc is one of the indispensable trace elements in the human body, and abnormal expression of metalloenzymes leads to abnormal absorption of elemental zinc, which causes tumorigenesis and tumor development (7). A review summarized evidence indicating that zinc metalloenzymes may be utilized for diagnostic and prognostic purposes in child brain tumors (8). Similar to aminopeptidase N (APN, also termed CD13), other zinc metalloenzymes are upregulated in multiple types of cancer and on the surface of vasculature undergoing angiogenesis (9).

The human carbonic anhydrase IV (CA4) gene, located on chromosome 17q22, was the first identified membrane-bound isozyme in the 16-member carbonic anhydrase (CA) gene family and contains 1,170 base pairs (10). The CA4 protein is a zinc metalloenzyme that catalyzes the reversible hydration and dehydration of $\mathrm{CO}_{2}$ and $\mathrm{HCO}_{3}^{-}(10)$. The $\mathrm{CA} 4$ enzyme is involved in the formation of gastric acid and participates in acid-base homeostasis (11). CA4 is expressed in normal human stomach tissues (11). CA2 is expressed at low levels in GC tissues (12). Similarly, CA9, another member of the carbonic anhydrase family, also exhibits loss of expression in GC (13). In contrast to CA2 and CA9, CA12 is highly expressed in GC (14). However, whether CA4 is expressed in GC has not yet been determined. The present study aimed to determine the expression of CA4 in GC tissues and assess its impact on cell proliferation. 


\section{Materials and methods}

Study subjects. Tissue samples (age range, 25-88; mean age \pm SD: $62.95 \pm 13.12$; males, 37; females, 34), including GC and adjacent normal mucosal tissues, were collected from surgically resected specimens obtained between April 2013 and December 2015. The distance between the tumor tissues and normal adjacent tissues was $5 \mathrm{~cm}$. Normal biopsy tissues (age range, 29-80; mean age \pm SD: 60.37 \pm 10.23 ; male, 17; female, 15) were collected from patients undergoing endoscopy between May 2015 and July 2015 at Ningbo First Hospital (Ningbo, China). As soon as the specimens were resected from the patients, tissue samples were obtained, preserved in RNA fixer (Bioteke Corporation) and stored at $-80^{\circ} \mathrm{C}$ until use. Paraffin-embedded specimens were collected from the Ningbo Diagnostic Pathology Center in August 2017. Approval was obtained from the Human Research Ethics Committee of Ningbo First Hospital. Each tumor was staged in accordance with the primary Tumor-Node-Metastasis (TNM) staging system (NCCN V.1.2011) (15). The included patients did not receive any neoadjuvant therapy. Inclusion criteria for the patients were as follows: i) Age $\geq 18$; ii) Informed consent obtained; and iii) Primary gastric cancer without chemotherapy or radiotherapy. Exclusion criteria for the patients were: i) Age <18; ii) Pregnancy or lactation; and iii) No full informed consent from the patient or his next of kin.

Cell lines and culture. A normal human gastric epithelial cell line (GES-1) and GC cell lines (AGS and HGC-27) were obtained from the Shanghai Institute of Biochemistry and Cell Biology, Chinese Academy of Sciences (Shanghai, China). Cells were cultured in RPMI-1640 medium (Gibco; Thermo Fisher Scientific, Inc.) supplemented with 10\% FBS (Gibco; Thermo Fisher Scientific, Inc.) in a humidified atmosphere containing $5 \% \mathrm{CO}_{2}$ at $37^{\circ} \mathrm{C}(16)$.

Plasmids, DNA and transfection. Human pcDNA3.1-CA4 and pcDNA3.1 clones were purchased from Thermo Fisher Scientific, Inc. Cells at $80 \%$ confluence were transfected with $1.5 \mu \mathrm{g}$ pcDNA3.1 negative control (trans-NC) or pcDNA3.1-CA4 (trans-CA4) vectors using Lipofectamine ${ }^{\circledR} 2000$ reagent (Thermo Fisher Scientific, Inc.) in 6-well plates according to the manufacturer's instructions. The transfected cells were cultured in Opti-MEM I Reduced Serum Medium (Thermo Fisher Scientific, Inc.) for $6 \mathrm{~h}$ and then in routine growth medium (RPMI-1640) for an additional $48 \mathrm{~h}$ before functional assays or protein expression analyses were performed.

Real-time analysis of cell proliferation. A Roche DP real-time cell analyzer (RTCA), an impedance-based xCELLigence System with E-Plates 96 (Roche Applied Science), was used to conduct proliferation assays as previously described (17). Impedance was measured by determining the cell index (CI).

Clonogenic assay. Cells were seeded into 6-well plates (500 cells/well) and cultured for 2 weeks. Colonies were then fixed with ethanol for $15 \mathrm{~min}$ and stained with $0.05 \%$ Giemsa for $1 \mathrm{~h}$ at room temperature. Each cell line was cultured in biological triplicate, and the surviving colonies (>50 cells/colony) were counted.
Table I. The specific primer sequences.

\begin{tabular}{ll}
\hline Gene & \multicolumn{1}{c}{ Primer sequence $\left(5^{\prime} \rightarrow 3^{\prime}\right)$} \\
\hline CA4 & F: TTGGTGGTGACGATGTTGAT \\
& R: CACTGGTGCTACGAGGTTCA \\
$\beta$-actin & F: GCTGTCACCTTCACCGTTCC \\
& R: CTCCATCCTGGCCTCGCTGT
\end{tabular}

CA4, carbonic anhydrase 4 .

Flow cytometric analysis of the cell cycle. The cell cycle distribution was analyzed using a BD FACSCalibur flow cytometer (BD Biosciences). A total of $1 \times 10^{6}$ GES- 1 and AGS cells/well were fixed with $70 \%$ ethanol and then propidium iodide (PI)/RNase staining buffer (QIAGEN GmbH) was added to stain the cells. Analysis was performed according to the manufacturer's instructions. Data were analyzed using Cell Quest Pro v5.1 software (BD Biosciences).

Total RNA extraction and reverse transcription-quantitative $(R T-q) P C R$. Total RNA was obtained from freshly cultured cells and human tissues using TRIzol ${ }^{\circledR}$ reagent (Invitrogen; Thermo Fisher Scientific, Inc.) according to the manufacturer's instructions. A NanoDrop spectrophotometer (Thermo Fisher Scientific, Inc.) was used to determine the concentrations and purity of RNA samples using the A260/A280 ratio (13). A GoTaq 2-Step RT-qPCR system (Promega Corporation) and an Mx3005P QPCR system (Stratagene; Agilent Technologies, Inc.) were used to assess the levels of CA4 and $\beta$-actin mRNA according to the manufacturer's instructions. The primer sequences are provided in Table I. All experiments were repeated in triplicate. The $-\Delta \mathrm{Ct}$ method was used to analyze the tissue samples, and the $2^{-\Delta \Delta \mathrm{Ct}}$ method was used for the relative quantification of gene expression in cell lines (18).

Western blotting. Radioimmunoprecipitation (RIPA) lysis buffer (Cell Signaling Technology, Inc.) was used to isolate total protein from GES-1/AGS cells transfected with pcDNA3.1-CA4 and pcDNA3.1. The protein concentration was quantified using Bradford assay reagents (Beyotime Institute of Biotechnology) according to the manufacturer's instructions; proteins $(20 \mu \mathrm{g})$ were separated by $12 \%$ sodium dodecyl sulfate-polyacrylamide gel electrophoresis and transferred to polyvinylidene fluoride membranes (EMD Millipore). The PVDF membranes were blocked in blocking solution (Beyotime Institute of Biotechnology) for $1 \mathrm{~h}$ in a shaker, and then washed 4 times with TBST for 5 min each time. The membranes were then incubated with primary antibodies at $4^{\circ} \mathrm{C}$ on a shaker overnight. Primary antibodies against CA4 (1:500; cat. no. sc-74527), cyclin-dependent kinase 2 (1:500; Cdk2; cat. no. sc-6248), Cyclin B1 (1:400; cat. no. sc-245), p21 (1:600; cat. no. sc-6246) and $\beta$-actin (dilution 1:1,000; cat. no. sc-47778) were obtained from Santa Cruz Biotechnology, Inc.. Horseradish peroxidase (HRP)-conjugated goat anti-mouse $\operatorname{IgG}(\mathrm{H}+\mathrm{L})(1: 1,000$; cat. no. A0216; Beyotime Institute of Biotechnology) and Western Bright ECL kits (Advansta, Inc.) were utilized to detect the desired proteins. Pre-stained protein molecular weight markers 
A

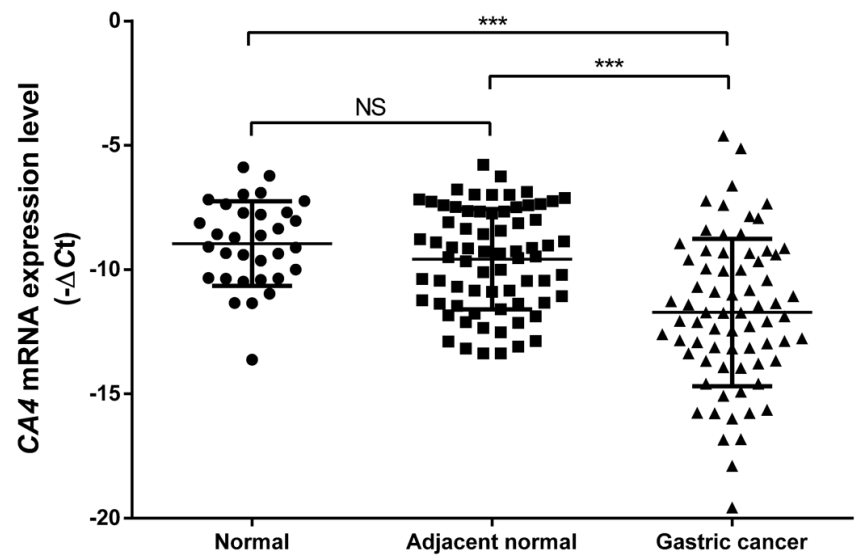

B
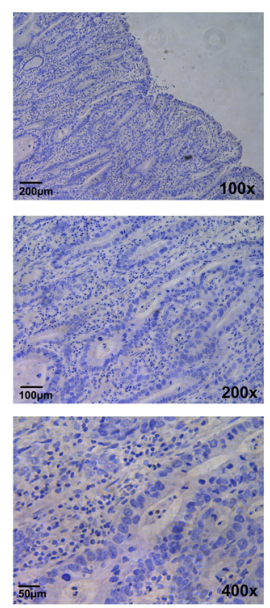

Gastric cancer
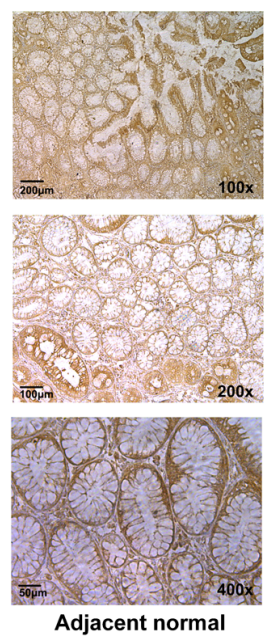

C

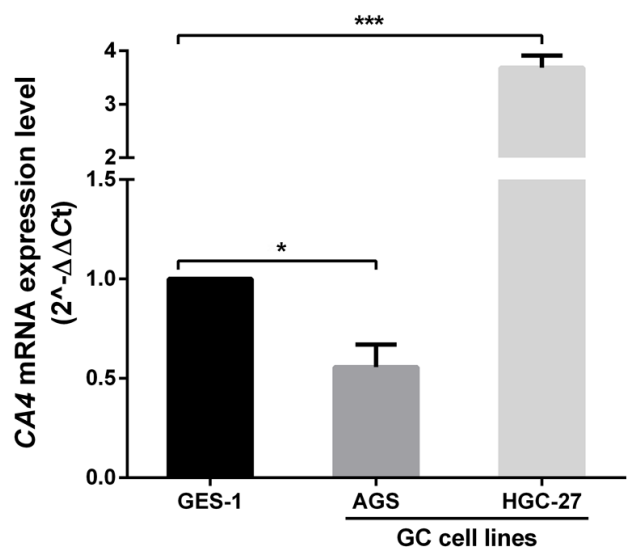

D

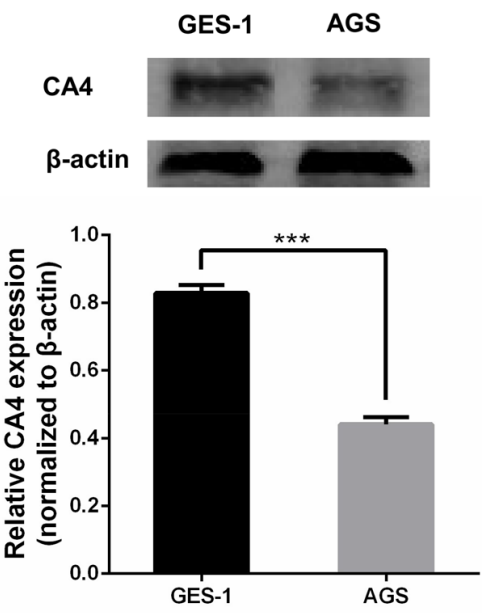

Figure 1. Downregulation of CA4 expression in GC tissues and cell lines. (A) The expression of CA4 mRNA was significantly downregulated in GC tumor tissues compared with adjacent normal tissues $(n=71)$ and normal biopsy tissues $(n=32)$ (normalized to $\beta$-actin); CA4 expression did not significantly differ between adjacent normal tissues and normal biopsy tissues. (B) Representative images of immunohistochemical staining of the CA4 protein in GC. (C) CA4 mRNA was expressed at lower levels in AGS cells compared with normal gastric mucosal GES-1cells, but was expressed at higher levels in HGC-27 cells. (D) Expression of CA4 in GC cells was confirmed by western blotting. ${ }^{*} \mathrm{P}<0.05,{ }^{* * * *} \mathrm{P}<0.001$. CA, carbonic anhydrase; GC, gastric cancer.

(Thermo Fisher Scientific, Inc.) were included in each gel. The results were analyzed using Image $\mathbf{J}$ software version 1.8 .0 (National Institute of Health).

Immunohistochemistry (IHC). Formalin-fixed paraffinembedded specimens were sliced into $2-\mu \mathrm{m}$ sections. After deparaffinization and dehydration, the sections were incubated with $0.3 \%$ hydrogen peroxide for $10 \mathrm{~min}$ for blocking. The sections were placed in EDTA buffer ( $\mathrm{pH}$ 8.0) and autoclaved at $100^{\circ} \mathrm{C}$ for $20 \mathrm{~min}$ for antigen retrieval and were then incubated with a primary anti-CA4 mouse monoclonal antibody (1:50; cat. no. sc-74527; Santa Cruz Biotechnology, Inc.) overnight at $4^{\circ} \mathrm{C}$, and an HRP-conjugated goat anti-mouse-IgG antibody $(1: 2,000$; cat. no. PV-9000; Beijing Zhongshan Jinqiao Biotechnology Co.; OriGene Technologies) was used as the secondary antibody and added for $30 \mathrm{~min}$ at $37^{\circ} \mathrm{C}$. A sample in which diluted PBS replaced the primary antibody during incubation served as a negative control. All sections were stained at the same time under the same conditions. All sections were observed by a light microscope (Olympus BX43; magnifications; x20 and x40).

IHC scoring. The histology of the samples was examined independently by two histopathologists blinded to the clinicopathological information. The sections were scored as previously described (19). The intensity of immunostaining was scored as negative (-, 0 points), weak (+, 1 point), moderate $(++, 2$ points), or strong (+++, 3 points). The percentage of positive tumor cells was assigned to five categories: i) $0-5 \%$, 0 points; ii) $6-25 \%, 1$ point; iii) $26-50 \%, 2$ points; iv) $51-75 \%$, 3 points; and v) $76-100 \%, 4$ points. The staining intensity and percentage of positive tumor cell scores were multiplied to determine the final score for each tumor specimen. The scores were grouped as low (which included scores between 0 and +4 ) and high (which included scores between +6 and +12 ).

Statistical analysis. Data are presented as the mean \pm standard deviation. The data were analyzed using SPSS Statistics 18.0 software (SPSS, Inc.) and GraphPad Prism 6.0 (GraphPad Software, Inc.). One-way analysis of variance, Pearson's $\chi^{2}$ and two-tailed Student's t-tests were used as appropriate. $\mathrm{P}<0.05$ was considered to indicate a statistically significant difference.

\section{Results}

CA4 expression is downregulated in GC tissues. GC tissues expressed lower levels of CA4 compared with the adjacent 
Table II. Clinicopathological features of CA4 in gastric cancer.

\begin{tabular}{|c|c|c|c|}
\hline \multirow[b]{2}{*}{ Feature } & \multicolumn{2}{|c|}{ CA4 } & \multirow[b]{2}{*}{ P-value } \\
\hline & Low $(\%)$ & High (\%) & \\
\hline Age, years & & & 0.580 \\
\hline$\geq 60$ & $13(61.9)$ & $8(38.1)$ & \\
\hline$<60$ & $9(75.0)$ & $3(25.0)$ & \\
\hline Sex & & & 0.696 \\
\hline Male & $16(69.6)$ & $7(30.4)$ & \\
\hline Female & $6(60.0)$ & $4(40.0)$ & \\
\hline Diameter, cm & & & 0.547 \\
\hline$\geq 5$ & $13(68.4)$ & $6(31.6)$ & \\
\hline$<5$ & $9(64.3)$ & $5(35.7)$ & \\
\hline Differentiation & & & 0.045 \\
\hline High & $8(80.0)$ & $2(20.0)$ & \\
\hline Moderate & $8(61.5)$ & $5(38.5)$ & \\
\hline Low & $6(60.0)$ & $4(40.0)$ & \\
\hline Lauren's classification & & & 0.163 \\
\hline Intestinal & $14(77.8)$ & $4(22.2)$ & \\
\hline Diffuse & $8(53.3)$ & $7(46.7)$ & \\
\hline Depth of invasion & & & 0.721 \\
\hline $\mathrm{T} 1-\mathrm{T} 2$ & $10(62.5)$ & $6(37.5)$ & \\
\hline T3-T4 & $12(70.6)$ & $5(29.4)$ & \\
\hline Lymphatic metastasis & & & 0.282 \\
\hline Negative & $13(76.5)$ & $4(23.5)$ & \\
\hline Positive & $9(56.2)$ & $7(43.8)$ & \\
\hline TNM stage & & & 0.465 \\
\hline I and II & $12(75.0)$ & $4(25.0)$ & \\
\hline III and IV & $10(58.8)$ & $7(41.2)$ & \\
\hline
\end{tabular}

CA4, carbonic anhydrase 4 .

gastric mucosa and normal biopsy tissues (Fig. 1A), but no significant difference was observed in CA4 expression between adjacent gastric mucosa and normal biopsy tissues (Fig. 1A). The expression of the CA4 protein in GC tissues was also investigated by immunohistochemistry (Fig. 1B). The results demonstrated that among the 39 cases, 84.6\% (33/39) patients exhibited low CA4 expression (score $<8$ ) and were used for analysis and presented in the table; however, the other $15.6 \%$ $(6 / 39)$ of cases displayed high CA4 expression (all 6 cases had $\geq 76 \%$ stained cells and a staining intensity score of 3 ) were excluded and their results were not presented (Table II).

The expression of CA4 in GC cell lines. The mRNA and protein levels of CA4 in two GC cell lines were investigated. CA4 mRNA expression was low in the AGS cell line and high in the HGC-27 cell line compared with that in the normal gastric mucosal cell line GES-1 (Fig. 1C). In addition, western blot analysis demonstrated that the protein expression levels of CA4 in AGS cells were also lower compared with those in GES-1 cells (Fig. 1D). Thus, the AGS and GES-1 cell lines were used in the subsequent functional study.
Table III. The association between CA4 mRNA expression levels in cancer tissues and clinicopathological factors of patients with gastric cancer.

\begin{tabular}{|c|c|c|c|}
\hline Characteristics & $\begin{array}{l}\text { No. of } \\
\text { patients }\end{array}$ & $\begin{array}{c}\text { CA4 level, }-\Delta \mathrm{Cq} \\
\text { mean } \pm \mathrm{SD}\end{array}$ & P-value \\
\hline Age & & & 0.360 \\
\hline$\geq 60$ & 44 & $-11.53 \pm 2.89$ & \\
\hline$<60$ & 27 & $-12.01 \pm 3.51$ & \\
\hline Sex & & & 0.764 \\
\hline Male & 37 & $-11.81 \pm 3.17$ & \\
\hline Female & 34 & $-11.57 \pm 3.07$ & \\
\hline Diameter, cm & & & 0.038 \\
\hline$\geq 5$ & 33 & $-12.58 \pm 3.34$ & \\
\hline$<5$ & 38 & $-10.97 \pm 2.73$ & \\
\hline CEA & & & 0.296 \\
\hline Positive & 40 & $-12.00 \pm 3.09$ & \\
\hline Negative & 31 & $-11.14 \pm 3.14$ & \\
\hline CA19-9 & & & 0.391 \\
\hline Positive & 32 & $-11.34 \pm 3.40$ & \\
\hline Negative & 39 & $-12.02 \pm 2.83$ & \\
\hline Depth of invasion & & & 0.039 \\
\hline $\mathrm{T} 1$ and $\mathrm{T} 2$ & 26 & $-10.65 \pm 2.26$ & \\
\hline $\mathrm{T} 3$ and $\mathrm{T} 4$ & 45 & $-12.25 \pm 3.36$ & \\
\hline Differentiation & & & 0.018 \\
\hline High & 7 & $-9.54 \pm 1.50$ & \\
\hline Moderate & 23 & $-11.67 \pm 2.23$ & \\
\hline Low & 41 & $-12.66 \pm 3.56$ & \\
\hline Lymphatic metastasis & & & 0.702 \\
\hline Negative & 24 & $-11.49 \pm 2.14$ & \\
\hline Positive & 47 & $-11.81 \pm 3.50$ & \\
\hline TNM stage & & & 0.321 \\
\hline I and II & 32 & $-11.35 \pm 1.99$ & \\
\hline III and IV & 39 & $-12.02 \pm 3.58$ & \\
\hline
\end{tabular}

CA4, carbonic anhydrase 4; CEA, carcinoembryonic antigen; CA19-9, carbohydrate antigen 19-9.

Associations between CA4 expression, pathological findings and tumor markers. The level of CA4 mRNA was associated with tumor size, depth of invasion and differentiation (Table III). With increasing pathological severity, the CA4 mRNA expression level decreased, however, this trend was not statistically significant. Simultaneously, no statistical difference was observed with any other pathological factors. Among the included patients, the rates of carcinoembryonic antigen (CEA) and carbohydrate antigen 19-9 (CA19-9) positivity were 56.3 and $45.1 \%$, respectively. In addition, the clinicopathological features of CA4 in GC tissues were also examined. According to the median score (IHC score=2) of CA4, the low expression patients $(n=33)$ presented in Table II were divided into two groups: 17 were considered weakly positive (IHC score 0-2), and 16 were selected as strongly positive (IHC score 3-6). In addition, the expression levels of CA4 were higher in female patients with GC 
A

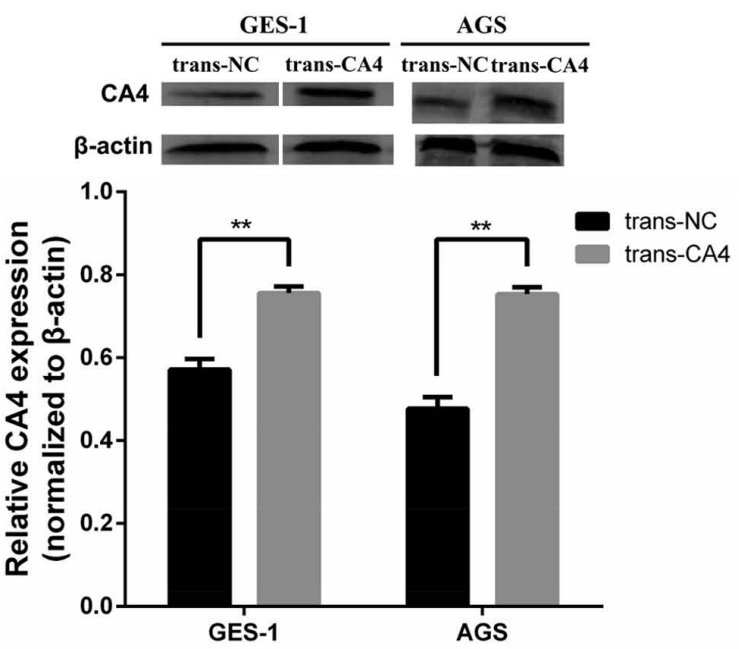

C

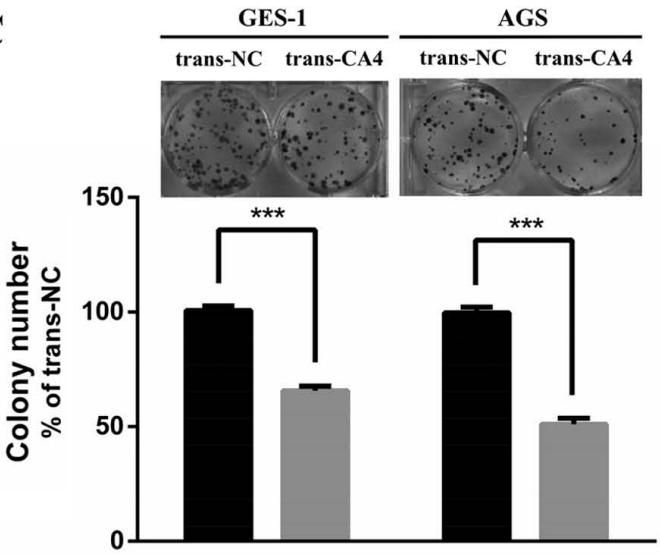

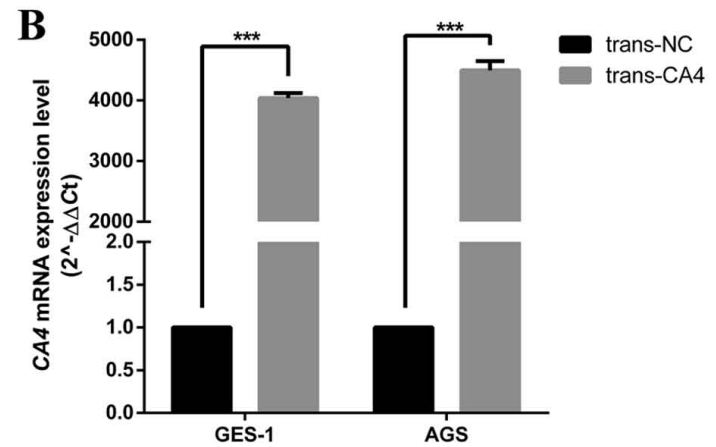

D
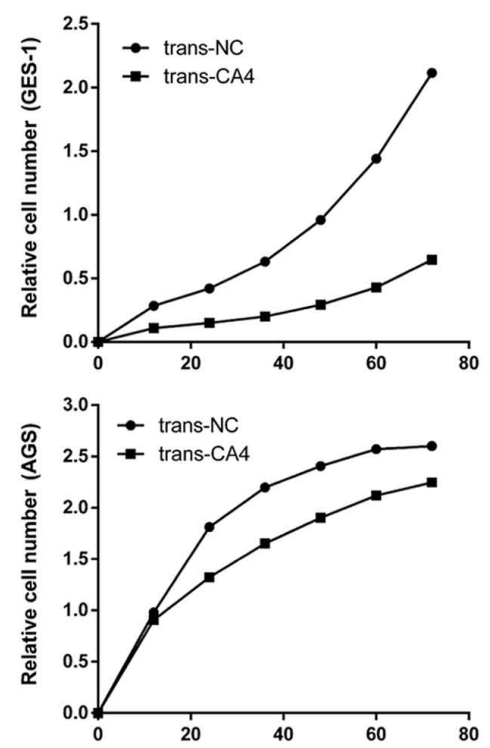

Figure 2. CA4 inhibits gastric cancer cell proliferation. (A) Ectopic expression of CA4 in the GES-1 and AGS cell lines was confirmed by western blotting. (B) Ectopic expression of CA4 in the GES-1 and AGS cell lines was confirmed by reverse transcription-quantitative PCR. (C) Colony formation was inhibited by CA4 overexpression in GES-1 and AGS cells. (D) Overexpression of CA4 in GES-1 and AGS cells inhibited cell proliferation, as confirmed by analysis with a real-time cell analyzer. ${ }^{* *} \mathrm{P}<0.01,{ }^{* * * *} \mathrm{P}<0.001$. CA, carbonic anhydrase; $\mathrm{GC}$, gastric cancer; $\mathrm{NC}$, negative control.

compared with those in male patients. The CA4 levels increased from well-differentiated GC tissues to moderately and poorly differentiated GC tissues (Table II).

Role of CA4 in cell proliferation. IHC and western blotting analysis demonstrated lower CA4 levels in AGS GC cells compared with those in GES-1 gastric epithelial cells (Fig. 1C and D); these cells were transfected with a CA4 expression vector to determine the biological functions of CA4 in human GC cells. Overexpression of CA4 protein and mRNA was confirmed by western blotting (Fig. 2A) and RT-qPCR (Fig. 2B), respectively. Based on the results of the clonogenic assay, fewer clones of a smaller size were observed in trans-CA4 cells compared with trans-NC cells (Fig. 2C).

Subsequently, the tumor-suppressive activity of CA4 was examined using a real-time cell analyzer. Trans-CA4 cells exhibited a significantly lower growth rate compared with that of trans-NC cells (Fig. 2D). Overexpression of CA4 effectively inhibited cell proliferation beginning at $24 \mathrm{~h}$ after transfection in both AGS and GES-1 cells.

Overexpression of CA4 in GES-1 and AGS cells arrests the cell cycle at the G2/Mphase. CA4 overexpression was associated with an increased population of trans-CA4 AGS cells in the G2/M phase (43.07\%) compared with that in trans-NC AGS cells (37.22\%; Fig. 3A). Similar findings were observed in trans-CA4-GES-1 cells. According to the western blot analysis, CA4 overexpression modulated the expression of $\mathrm{G} 2 / \mathrm{M}$ phase-related proteins; the levels of Cdk2 and cyclin B1 were decreased, and the levels of p21 were increased compare with those in trans-NC cells (Fig. 3B).

\section{Discussion}

The results of the present study demonstrated that CA4 was expressed at lower levels in GC tissues compared with those in adjacent normal tissues and normal biopsy tissues, and its level was associated with sex, tumor size, depth of invasion and differentiation. The results of the present study also indicated that CA4 overexpression was associated with the inhibition of cell proliferation and the cell cycle of AGS and GES-1 cells, possibly by modulating the expression of cell cycle-associated proteins. To the best of our knowledge, the present study was the first to identify the clinical and biological functions of CA4 in GC. CA4 was previously studied in colon cancer by Zhang et al (20), who reported that CA4 exhibited tumor-suppressing properties. In addition, CA4 methylation levels serve as a prognostic factor 
A
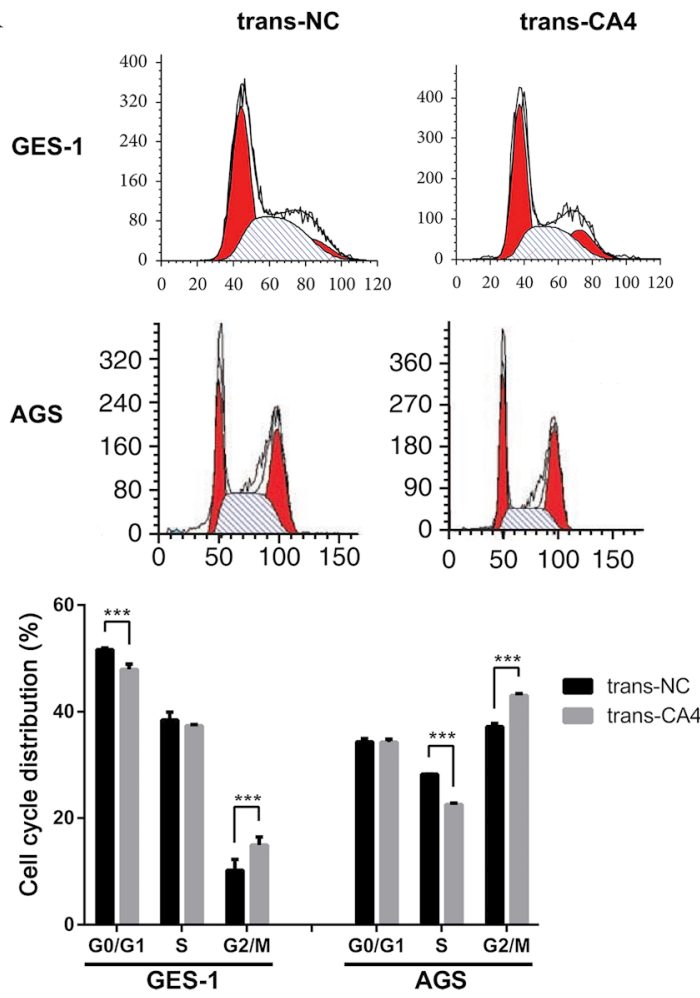

B
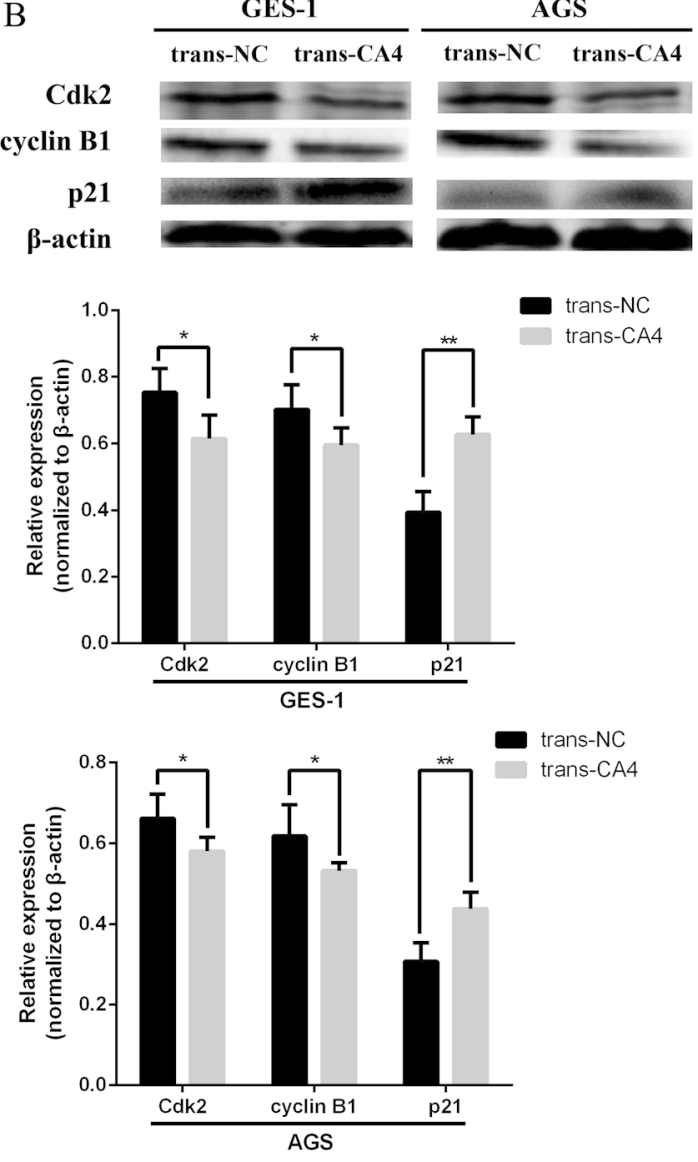

Figure 3. Overexpression of CA4 induces cell cycle arrest in GES-1 and AGS cells. (A) According to flow cytometric analysis, CA4 increased the population of GES-1 cells in G2/M phase, but decreased the population in G0/G1 phase and increased the population of AGS cells in G2/M phase, but decreased the population in $\mathrm{S}$ phase. (B) Ectopic expression of CA4 reduced the protein levels of $\mathrm{Cdk} 2$ and cyclin $\mathrm{B} 1$ and increased the protein level of the p21. ${ }^{*} \mathrm{P}<0.05,{ }^{* *} \mathrm{P}<0.01$ and ${ }^{* * *} \mathrm{P}<0.001$. CA, carbonic anhydrase; Cdk2, cyclin-dependent; kinase 2 ; NC, negative control. for colon cancer recurrence (20). Overexpression of CA4 in transfected cells suppresses the proliferative and migratory abilities of colon cancer cells (20).

In addition to CA4, other members of the carbonic anhydrase family have been reported to possess cancer-associated functions; however, only CA2, CA9 and CA12 have been reported to be associated with GC. According to Hu et al (12), downregulation of CA2 expression is associated with tumor aggressiveness and may predict the overall survival of patients with GC. Fidan et al (21), demonstrated that CA9 levels were increased in patients with GC compared with healthy controls, suggesting that CA9 may be used as a biomarker to predict the occurrence of GC. Leppilampi et al (14), confirmed that CA12 expression was slightly increased in gastric adenocarcinoma samples compared with non-neoplastic gastric mucosa samples. In the present study, the expression levels of CA4 were examined in two GC cell lines (AGS and HGC-27): The AGS cell line was ultimately selected as the CA4 mRNA and protein expression levels were lower in AGS cells compared with those in GES-1 cells; the expression of CA4 in HGC-27 GC cells was higher compared with that in GES-1 cells, which may be related to tumor heterogeneity. Similarly, CA4 was not downregulated in all GC tissues, but was upregulated in a small number of GC tissues. A series of functional experiments in the present study confirmed that CA4 overexpression inhibited the proliferation of AGS cells, suggesting a tumor-suppressive role of CA4 in this GC cell line. However, the inhibitory effect of CA4 on cell proliferation is not only reflected in GC cell lines, its overexpression also inhibits the growth of GES-1. Further research indicated that the inhibition of cell proliferation may be related to cell cycle arrest. The cell cycle distribution analysis results indicated that CA4 overexpression arrested AGS and GES-1 in the G2/M phase. The overexpression of CA4 caused a significant reduction in the $\mathrm{S}$ phase of AGS cells, while GES-1 cells were significantly reduced in the G0/G1 phase. This result revealed that $\mathrm{CA} 4$ impacts on $\mathrm{GC}$ cells as well as normal cells. If used in the clinical treatment of GC, CA4 needs a more specific therapeutic target. In subsequent analysis in the present study, CA4 overexpression was associated with reduced expression of cyclin B1 and Cdk2, and increased expression of p21, the key Cdk inhibitor, compared with the NC group. In the G2/M phase of the GC cell cycle, cyclin B1 and Cdk2 are upregulated, and p21 is expressed at low levels (22-25). Based on the results from the present study, CA4 suppression may be responsible for the alterations in the expression of these regulatory proteins in GC.

Commonly used biomarkers, such as CEA or CA19-9, were detected at low rates in GC, as demonstrated in the present study. Consistent with these findings, the positive detection rates of CEA and CA19-9 in another study were 64.0 and 53.3\%, respectively (26). Therefore, CA4 may serve as a more sensitive biomarker compared with CEA or CA19-9 for the detection of GC.

Limitations of the present study should be acknowledged. Only 71 GC samples were used in this study. Additional analyses with a larger sample size may further define the clinical value of CA4 in GC. In addition, the role of CA4 in tumorigenesis requires further research.

In conclusion, CA4 may act as a tumor suppressor gene in $\mathrm{GC}$ by arresting cell division in G2/M phase. Future studies should investigate whether CA4 is useful for the diagnosis and treatment of GC to improve the survival of patients with GC. 


\section{Acknowledgements}

Not applicable.

\section{Funding}

The present study was supported by The Natural Science Foundation of Zhejiang (grant no. LQ18H160015), The Natural Science Foundation of Ningbo (grant nos. 2014A610226 and 2016A610158) and The Scientific Benefit for People Project of Ningbo (grant no. 2014C51001).

\section{Availability of data and materials}

All data generated or analyzed during this study are included in this published article.

\section{Authors' contributions}

BW, XD and HS conceived and designed the experiments, and wrote the article. BW, HJ, XW, YW and PL performed the experiments. HJ, XZ and JG analyzed the data. All authors have read and approved the manuscript.

\section{Ethics approval and consent to participate}

Approval was obtained from the Human Research Ethics Committee of Ningbo First Hospital (approval no. 2018-R045). Written informed consent was provided by all participants.

\section{Patient consent for publication}

Not applicable.

\section{Competing interests}

The authors declare that they have no competing interests.

\section{References}

1. Shi J, Qu YP and Hou P: Pathogenetic mechanisms in gastric cancer. World J Gastroenterol 20: 13804-13819, 2014.

2. Bray F, Ferlay J, Soerjomataram I, Siegel RL, Torre LA and Jemal A: Global cancer statistics 2018: GLOBOCAN estimates of incidence and mortality worldwide for 36 cancers in 185 countries. CA Cancer J Clin 68: 394-424, 2018.

3. Ko KP, Shin A, Cho S, Park SK and Yoo KY: Environmental contributions to gastrointestinal and liver cancer in the asia-pacific region. J Gastroenterol Hepatol 33: 111-120, 2018.

4. Suzuki H, Oda I, Abe S, Sekiguchi M, Mori G, Nonaka S, Yoshinaga $S$ and Saito Y: High rate of 5-year survival among patients with early gastric cancer undergoing curative endoscopic submucosal dissection. Gastric Cancer 19: 198-205, 2016.

5. Tanabe S, Ishido K, Higuchi K, Sasaki T, Katada C, Azuma M, Naruke A, Kim M and Koizumi W: Long-term outcomes of endoscopic submucosal dissection for early gastric cancer: A retrospective comparison with conventional endoscopic resection in a single center. Gastric Cancer 17: 130-136, 2014.

6. Ohnita K, Isomoto $\mathrm{H}$, Shikuwa S, Yajima $\mathrm{H}$, Minami $\mathrm{H}$, Matsushima K, Akazawa Y, Yamaguchi N, Fukuda E, Nishiyama H, et al: Early and long-term outcomes of endoscopic submucosal dissection for early gastric cancer in a large patient series. Exp Ther Med 7: 594-598, 2014.

7. Skrajnowska D and Bobrowska-Korczak B: Role of zinc in immune system and anti-cancer defense mechanisms. Nutrients 11: 2273, 2019.
8. Hrabeta J, Eckschlager T, Stiborova M, Heger Z, Krizkova S and Adam V: Zinc and zinc-containing biomolecules in childhood brain tumors. J Mol Med (Berl) 94: 1199-1215, 2016.

9. Schreiber CL and Smith BD: Molecular imaging of aminopeptidase $\mathrm{N}$ in cancer and angiogenesis. Contrast Media Mol Imaging 2018: 5315172, 2018.

10. Waheed A and Sly WS: Membrane associated carbonic anhydrase IV (CA IV): A personal and historical perspective. Subcell Biochem 75: 157-179, 2014.

11. Fleming RE, Parkkila S, Parkkila AK, Rajaniemi H, Waheed A and Sly WS: Carbonic anhydrase IV expression in rat and human gastrointestinal tract regional, cellular, and subcellular localization. J Clin Invest 96: 2907-2913, 1995.

12. Hu X, Huang Z, Liao Z, He C and Fang X: Low CA II expression is associated with tumor aggressiveness and poor prognosis in gastric cancer patients. Int J Clin Exp Pathol 7: 6716-6724, 2014.

13. Chen J, Röcken C, Hoffmann J, Krüger S, Lendeckel U, Rocco A, Pastorekova S, Malfertheiner P and Ebert MP: Expression of carbonic anhydrase 9 at the invasion front of gastric cancers. Gut 54: 920-927, 2005.

14. Leppilampi M, Saarnio J, Karttunen TJ, Kivelä J, Pastoreková S, Pastorek J, Waheed A, Sly WS and Parkkila S: Carbonic anhydrase isozymes IX and XII in gastric tumors. World J Gastroenterol 9: 1398-1403, 2003.

15. Ajani JA, Bentrem DJ, Besh S, D'Amico TA, Das P, Denlinger C, Fakih MG, Fuchs CS, Gerdes H, Glasgow RE, et al: Gastric cancer, version 2.2013: Featured updates to the NCCN guidelines. J Natl Compr Canc Netw 11: 531-546, 2013.

16. Jiang Z, Guo J, Xiao B, Miao Y, Huang R, Li D and Zhang Y: Increased expression of miR-421 in human gastric carcinoma and its clinical association. J Gastroenterol 45: 17-23, 2010.

17. Deng H, Guo Y, Song H, Xiao B, Sun W, Liu Z, Yu X, Xia T, Cui L and Guo J: MicroRNA-195 and microRNA-378 mediate tumor growth suppression by epigenetical regulation in gastric cancer. Gene 518: 351-359, 2013.

18. Zhou H, Guo JM, Lou YR, Zhang XJ, Zhong FD, Jiang Z, Cheng J and Xiao BX: Detection of circulating tumor cells in peripheral blood from patients with gastric cancer using microRNA as a marker. J Mol Med (Berl) 88: 709-717, 2010.

19. Shi R, Liu W, Liu B, Xu Z, Chen L and Zhang Z: Slit2 expression and its correlation with subcellular localization of beta-catenin in gastric cancer. Oncol Rep 30: 1883-1889, 2013.

20. Zhang J, Tsoi H, Li X, Wang H, Gao J, Wang K, Go MY, Ng SC, Chan FK, Sung JJ and Yu J: Carbonic anhydrase IV inhibits colon cancer development by inhibiting the wnt signalling pathway through targeting the WTAP-WT1-TBL1 axis. Gut 65: 1482-1493, 2016.

21. Fidan E, Mentese A, Ozdemir F, Deger O, Kavgaci H, Karahan SC and Aydin F: Diagnostic and prognostic significance of CA IX and suPAR in gastric cancer. Med Oncol 30: 540, 2013.

22. Begnami MD, Fregnani JH, Nonogaki S and Soares FA: Evaluation of cell cycle protein expression in gastric cancer: Cyclin B1 expression and its prognostic implication. Hum Pathol 41: 1120-1127, 2010.

23. Lee SM, Kwon JI, Choi YH, Eom HS and Chi GY: Induction of G2/M arrest and apoptosis by water extract of strychni semen in human gastric carcinoma AGS cells. Phytother Res 22: 752-758, 2008.

24. Zhang R, Li YX, Wang LS, Song Y, Huang QJ and Zhang DG: Aqueous extracts of fructus ligustri lucide induce gastric carcinoma cell apoptosis and G2/M cycle arrest. Int J Clin Exp Med 8: 12307-12316, 2015.

25. Zhang C, Chen Z, Zhou X, Xu W, Wang G, Tang X, Luo L, Tu J, Zhu Y, Hu W, et al: Cantharidin induces G2/M phase arrest and apoptosis in human gastric cancer SGC-7901 and BGC-823 cells. Oncol Lett 8: 2721-2726, 2014.

26. Song H, Sun W, Ye G, Ding X, Liu Z, Zhang S, Xia T, Xiao B, $\mathrm{Xi} \mathrm{Y}$ and Guo J: Long non-coding RNA expression profile in human gastric cancer and its clinical significances. J Transl Med 11: 225, 2013.

This work is licensed under a Creative Commons Attribution-NonCommercial-NoDerivatives 4.0 International (CC BY-NC-ND 4.0) License. 